\title{
Pharmacological Approach for Managing Pain in Irritable Bowel Syndrome: A Review Article
}

\author{
Longtu Chen, ${ }^{1}$ Sheikh J. Ilham, ${ }^{1}$ and Bin Feng ${ }^{1,}{ }^{*}$ \\ ${ }^{1}$ Department of Biomedical Engineering, University of Connecticut, Storrs, CT 06269, USA \\ "Corresponding author: Bin Feng, Ph.D., Department of Biomedical Engineering, University of Connecticut, 260 Glenbrook Road, Unit 3247, Storrs, CT 06269-3247, USA. Tel: \\ +1-8604866435, Fax: +1-8604862500, E-mail: fengb@uconn.edu
}

Received 2016 October 03; Revised 2016 December 02; Accepted 2016 December 24.

\begin{abstract}
Context: Visceral pain is a leading symptom for patients with irritable bowel syndrome (IBS) that affects $10 \%-20 \%$ of the world population. Conventional pharmacological treatments to manage IBS-related visceral pain is unsatisfactory. Recently, medications have emerged to treat IBS patients by targeting the gastrointestinal (GI) tract and peripheral nerves to alleviate visceral pain while avoiding adverse effects on the central nervous system (CNS). Several investigational drugs for IBS also target the periphery with minimal CNS effects.

Evidence of Acquisition: In this paper, reputable internet databases from 1960 - 2016 were searched including Pubmed and ClinicalTrials.org, and 97 original articles analyzed. Search was performed based on the following keywords and combinations: irritable bowel syndrome, clinical trial, pain, visceral pain, narcotics, opioid, chloride channel, neuropathy, primary afferent, intestine, microbiota, gut barrier, inflammation, diarrhea, constipation, serotonin, visceral hypersensitivity, nociceptor, sensitization, hyperalgesia.

Results: Certain conventional pain managing drugs do not effectively improve IBS symptoms, including NSAIDs, acetaminophen, aspirin, and various narcotics. Anxiolytic and antidepressant drugs (Benzodiazepines, TCAs, SSRI and SNRI) can attenuate pain in IBS patients with relevant comorbidities. Clonidine, gabapentin and pregabalin can moderately improve IBS symptoms. Lubiprostone relieves constipation predominant IBS (IBS-C) while loperamide improves diarrhea predominant IBS (IBS-D). Alosetron, granisetron and ondansetron can generally treat pain in IBS-D patients, of which alosetron needs to be used with caution due to cardiovascular toxicity. The optimal drugs for managing pain in IBS-D and IBS-C appear to be eluxadoline and linaclotide, respectively, both of which target peripheral GI tract.

Conclusions: Conventional pain managing drugs are in general not suitable for treating IBS pain. Medications that target the GI tract and peripheral nerves have better therapeutic profiles by limiting adverse CNS effects.
\end{abstract}

Keywords: Irritable Bowel Syndrome, Clinical Trial, Visceral Pain, Visceral Hypersensitivity, Hyperalgesia, Diarrhea, Constipation

\section{Introduction}

Visceral pain, i.e., pain arising from the viscera is the cardinal symptom of patients with irritable bowel syndrome (IBS), a prevalent disease afflicting 10\% - $20 \%$ of the world population (1-3). IBS patients generally experience enhanced sensation to normal bowel functions, reduced perception threshold and tenderness in somatic referral, which are manifestations of peripheral and central hyperalgesia of the nervous system (4). Unlike other hyperalgesia that is often accompanied by tissue injury and inflammation, apparent structural damage in IBS colon is lacking. Thus, diagnosis of IBS generally resorts to symptomatic classification following the "Rome III" or the most recent "Rome IV" criteria established from epidemiological analysis and clinical experience $(5,6)$. Symptomatically, IBS patients can be categorized into constipation predominant (IBS-C), diarrhea predominant (IBS-D), mixed constipation and diarrhea (IBS-M), and unsubtyped (IBS-U) sub- groups. The etiology of IBS remains undetermined and has been under constant investigation which suggests contributions from negative life experience $(7,8)$, psychological disorders (9), genetic predisposition (10) and environmental contributions $(11,12)$. The post-infectious IBS (PI-IBS), a subset of IBS appears to be caused by an acute infectious gastroenteritis, i.e., a bout of bacterial infection in the stomach and intestines (13). In addition, increased gut permeability has been linked to the development of IBS symptoms (14). Recently, difference in intestinal microbiota has been discovered between IBS patients and healthy population, suggesting abnormality of intestinal microbiota as a causal factor of IBS (15).

Visceral pain associated with IBS has been attributed to the malfunction of the brain-gut axis in the nervous system (16). Central sensitization from abnormal information processing by the central nervous system (CNS) and/or dysregulated CNS modulation clearly play a key role in chronic 
visceral pain, which is implicated by enhanced perception of normal sensory signal input as pain and descending modulation incapable of suppressing persistent pain (17). However, like in many chronic pain conditions, prolonged visceral pain in IBS is initiated by activities in peripheral sensory (afferent) neurons $(4,18,19)$. This is readily supported by simple clinical and preclinical experiments of blocking afferent input into the CNS. Indeed, infusion of local anesthetics into the rectum significantly relieves discomfort and pain in IBS patients and animal models, including relief of referred abdominal hyperalgesia (tenderness) (20-22). In contrast, rectal infusion of glycerol, an intestinal mucosal irritant, enabled healthy volunteers experience IBS-like symptoms, include visceral hyperalgesia and referred tenderness (23). Recent success of several peripherally restricted drugs has further confirmed that targeting the periphery organs and nerves is viably strategy to manage IBS-related pain.

This review will be focused on the current medications available for treating IBS, especially their therapeutic profiles (benefits vs. side effects) in managing visceral pain. Due to space limitations, excluded in this review are nonpharmacological treatments (e.g., acupuncture, hypnotherapy and psychotherapy) and drugs/mixtures that lack well-defined pharmacological targets, (e.g., antispasmodics, dietary fibers, bulking agents, probiotics, prebiotics and herbal medicines). We will first summarize categories of conventional pain managing drugs that were historically adopted to treat visceral pain in IBS. Then, particular focus will be given to drugs available to IBS patients that target the gastrointestinal (GI) tract and peripheral nerves, which generally have minimum off-target side effects on the CNS. Last, we will survey the most recent advances in candidate pharmacological targets and investigational drugs for treating IBS.

\section{Conventional Pain Managing Drugs Adopted For The Viscera}

Visceral pain is less defined and often poorly and unreliably localized clinically. This is likely caused by the complexity of the neuroanatomic innervation of the visceral organs consisting of web-like neural plexus throughout the thoracic and abdominal cavities with central projections from each visceral organ to multiple vertebral segments of the spinal cord (24). Accordingly, our understanding about visceral pain lags behind other types of pain. It is thus common practice for clinicians to adopt conventional pain managing drugs to treat visceral pain patients. Summarized below are four categories of drugs generally prescribed to IBS patients in the clinics.
Non-steroidal anti-inflammatory drugs (NSAIDs), acetaminophen and aspirin are used to treat bowel pain because of the analgesic and anti-inflammatory effects. However, the efficacy of these drugs in treating IBS pain does not seem to be supported by any systematic studies or formal clinical trials. On the other hand, long-term use of all these drugs are associated with chronic constipation (25). Further, NSAIDs appear to have negative effects on IBS patients as evidenced by a close correlation between frequent use of NSAID and development of IBS symptoms (26) as well as compromised intestinal permeability in IBS patients using NSAIDs (27-29). Other adverse effects of NSAIDS and aspirin include enteropathy, mucosal damage, intestinal strictures, ulcers, colitis and rectitis. Acetaminophen can cause liver necrosis and fatal liver damage when overdosed $(30,31)$. Based upon the above evidence, NSAIDs may not be recommended for treating IBS pain.

Narcotics consisting of morphine, heroin and derivatives effectively suppress pain mainly by mediating the opioid receptors in the central nervous system. Despite their anti-nociceptive benefits, narcotics come with several significant side effects from non-specific targeting of the CNS, including habituation, dependence, addiction, and opioid-induced hyperalgesia. In addition, narcotics negatively affect the gastrointestinal tract by causing nausea and vomiting, constipation, delay in GI transit, and more importantly the development of narcotic bowel syndrome (NBS) that actually enhances abdominal pain (32, 33). Narcotics appear to be effective in alleviating acute visceral pain, but their long-term efficacy on IBS pain has not been supported by any large-scaled clinical studies. In light of the severe side effects and moderate benefits, narcotics should not be prescribed to IBS patients with chronic visceral pain.

Benzodiazepines that are effective in treating psychiatric disorders are also commonly used for IBS patients as both type of disorders often co-exist. Benzodiazepines (BZD) function as a GABAA receptor enhancer to inhibit neural activities mainly at the central nervous system (34). It is safe to treat psychiatric disorders using benzodiazepines for short-term use, whereas long-term use of BZD leads to cognitive impairment and other adverse mental and physical effects (35). Various forms of benzodiazepines have been extensively investigated for managing IBS symptoms (36), among which dextofisopam even reached Phase IIb clinical trial but failed to demonstrate any significant anti-nociceptive benefits (37). Thus, the BZD should be considered mainly for treating some IBS patients comorbid with anxiety.

Tricyclic antidepressants (TCAs) are commonly selected for treating IBS symptoms. Most TCAs act as serotonin-norepinephrine reuptake inhibitors but also 
have antagonistic/agonistic effect at several serotonin receptor subtypes, NMDA receptors and sigma receptors. Compared to the treatment of depression, a lower dose of TCAs is used in treating IBS, which is supported by several studies to improve the global symptoms of IBS and reduce pain perception and discomfort especially for IBS-D patients $(38,39)$. However, due to severe adverse effects including hypotension, drowsiness and constipation, TCAs are not among the first choices for the treatment of IBS, and should be carefully used $(38,39)$.

Selective serotonin reuptake inhibitors (SSRIs) and serotonin-norepinephrine reuptake inhibitors (SNRIs) have more confined pharmacological targets than TCAs and have undergone extensive investigation for efficacy in managing IBS symptoms, among which fluoxetine, citalopram, and paroxetine all went to clinical trials. Fluoxetine significantly mitigate pain perception, improve bloating symptom and stool consistency in a 12-week clinical study (40), which nevertheless conflicts with the outcome of another 6-week trial (41). Outcomes from clinical trials of citalopram are also controversy with some showing improved IBS symptom (42) and others insignificant effects $(43,44)$. Paroxetine could improve overall well-being in a 12-week trial, but, symptoms of IBS are not significantly improved (45). Besides unclear efficacy in the treatment of IBS, adverse effects of taking SSRIs and SNRIs include agitation, insomnia and nausea. Thus, SSRIs and SNRIs appears only have moderate effect in alleviating IBS symptoms and should be prescribed to IBS patients comorbid with depression.

Clonidine, an alpha-2 adrenergic agonist, has proved to relieve certain IBS symptoms, including attenuating fast colonic tone, reducing postprandial gastric volume, alleviating abdominal pain sensation and enhancing colonic compliance $(46,47)$. All these effects collectively benefit patients to mitigate the discomfort of IBS. Commonly seen adverse effects of clonidine includes drowsiness, dry mouth and sleep problems, which limit the wide use of clonidine in the treatment of IBS $(46,47)$.

Gabapentin and pregabalin have been recently recommended for treating IBS pain which are widely used for managing neuropathic pain in diabetic neuropathy, fibromyalgia and post-herpetic neuralgia etc $(48,49)$. Gabapentin and pregabalin were originally designed as analogs of GABA but were found to have no binding affinity with GABA receptors. Studies have indicated that the pain relieving effect of gabapentin and pregabalin is through binding with $\alpha 2 \delta-1$, an auxiliary subunit of voltage gated calcium channels. The use of gabapentin and pregabalin to treat IBS symptom is supported by two clinical studies of small scale, in which symptoms of abdominal pain, urgency, and bloating were significantly improved $(50,51)$.
Adverse effects include dizziness and drowsiness. The therapeutic benefits of gabapentin and pregabalin in treating IBS pain requires further confirmation by large-scaled clinical studies.

\section{Peripherally Restricted Drugs For Managing Visceral Pain}

The aforementioned generic pain-managing drugs are either ineffective or moderate in managing IBS-related pain. In addition to suppressing pain perception, they often affect other CNS regions to cause various adverse effects that out-weight the therapeutic benefits. Alternatively, drugs that target the peripheral organs and nerves can potentially enhance the therapeutic profile by minimizing off-target side effects. Thus, primary afferent neurons, especially nociceptors have become the target for pharmacological modulation in treating visceral pain and other types of chronic pain (52). Nociceptor sensitization necessary for prolonged visceral pain is orchestrated by an array of membrane ion channels, intracellular molecules and messengers (see an elaborated review (52) for details), which in theory are all valid pharmacological targets for IBS pain (53). However, only a short list of drugs targeting the periphery have emerged and all are reviewed below.

\section{Serotonergic Agonist/Antagonist}

Serotonin, despite being an important neurotransmitter in the CNS, is mostly (> 90\%) present in enterochromaffin cells (ECs) in the GI tract (54). Release of serotonin in the intestine results in smooth muscle contraction or relaxation, GI transit time alternation and luminal secretion. Recent works have revealed that 5-HT3 and 5-HT4 receptors are located in the mucosa of the small and large intestines and on epithelial and ECs of distal colon (55). Stimulation of the 5-HT4 receptors results in smooth muscle relaxation, whereas stimulation of 5-HT3 causes smooth muscle contraction. In addition, neural activities of visceral afferent neurons were reportedly suppressed by blockage of 5-HT3 receptors in animal studies (56). So far, three drugs of this category are available for IBS patients, which are all 5-HT3 receptor antagonists.

Alosetron is one of the 5-HT3 receptor antagonists for treating IBS-D patients. Studies, based on clinical trials, have demonstrated the efficacy of alosetron in the symptomatic treatment of IBS-D resulting in improved fecal discharge pattern, reduced urgency, and relief from abdominal pain (57). Alosetron's 5-HT3 antagonism decelerates the process of fecal discharge through the large intestine, increase water absorption in the gut wall and control the 
moisture content and volume of the remaining waste particles. The duration of action is longer in male than in female patients. Alosetron was initially approved by the FDA in 2000 for the treatment of female patients with IBS$\mathrm{D}$, withdrawn from the market for two years due to case reports of ischemic colitis and complicated constipation, and reintroduced for more than a decade under a risk managing program. The usage of this drug has been kept very limited, such as, for patients who have experienced IBS symptoms for at least six months, and have not responded adequately to conventional therapy (58).

Granisetron and ondansetron are two other 5-HT3 receptor antagonists that are less potent than alosetron, and they are widely used to alleviate nausea and vomiting derived from cancer chemotherapy. Efficiency of both drugs in IBS were supported by the outcomes of several clinical studies. Granisetron significantly reduces rectal sensitivity to balloon distension in 12 IBS patients in a dosedependent manner. Postprandial motility is also reduced by granisetron (59). In a separate study, ondansetron relieved pain perception by significantly increasing rectal sensory threshold to electrical stimulation, and patients suffered fewer times of daily pain after taking ondansetron (60). From another large scaled clinical trial on 120 IBSD patients, ondansetron significantly improved stool consistency, increased GI transit time and relieved urgency and intestinal bloating in many IBS-D patients. However, the pain-relieving effect of ondansetron was not systematically explored in the study (61). From the above evidence, granisetron and ondansetron are deemed to possess potential efficacy in treating IBS-D patients. The most common adverse effect is constipation.

\section{Peripherally Restricted Opioids}

Opioids can affect both the central and peripheral nervous systems. In addition to profound modulatory effect to the CNS, opioids can modify GI function by binding with opioid receptors on the enteric circuitry and primary afferent nerve endings (62). Opioid receptors in the GI tract play major roles in regulating GI motility, secretion, and visceral sensation (63). Opioid receptors are divided into three major categories: the $\mu$-opioid, $\kappa$-opioid, and $\delta$ opioid receptors, all of which are G-protein coupled receptors. Although each class of receptors differs in their responsiveness to different agonists, in general they all work via inhibition of adenylyl cyclase and cyclic adenosine monophosphate formation, inhibition of N-type calcium channels, and neuronal hyperpolarization via inwardly rectifying potassium channels (63). Usually, $\mu$-opioid receptor agonists inhibit smooth muscle contractile activity resulting in constipation. Delta-opioid agonists are more likely to exhibit their inhibitory effects on GI circular muscle. And $\kappa$-opioid receptors play roles in GI propulsion and visceral sensation. Among this category of drugs, loperamide and eluxadoline are available for treating IBS-D patients (63).

Loperamide, a synthetic peripheral $\mu$-opioid receptor agonist, is nonabsorbable with low bioavailability and incapable of diffusing through the blood-brain-barrier. Thus, loperamide lacks the array of central opioid-like adverse effect and restricts its effects within the GI tract. It is originally used with strictly precise dosage for acute diarrhea treatment. Use of loperamide to treat IBS patients have been supported by several clinical studies (64-66). Apparent efficacy was observed after 3 - 5 weeks of treatment demonstrating global symptom improvements, reduced abdominal pain, and increased stool consistency. Common side effects of loperamide include nausea, cramping and constipation. In particular, the aggravated constipation symptom has limited its usage on IBS-C patients.

Eluxadoline, a newly FDA-approved drug for the treatment of IBS-D, is an orally active $\mu$-opioid receptor agonist and $\delta$-opioid receptor antagonist, with both the antidiarrheal and analgesic effects (67). The action of eluxadoline is restricted only in the GI tract, and scarcely has any hazardous effect in the CNS (68). Different studies have demonstrated that eluxadoline can attenuate visceral hypersensitivity without complete inhibition of GI motility (63). In the first place, as a $\mu$-opioid receptor, eluxadoline slows down GI motility, decreases visceral sensation, and inhibits secretion. In the second place, as a $\delta$-opioid receptor antagonist, eluxadoline counteracts with some of the $\mu$-opioid effects, usually identified as adverse effects, such as excessive slowing of motility and reinforcement of $\mu$ and $\kappa$-opioid receptor-mediated effects on visceral sensation (68). Hence, this drug possesses almost all of the advantages of its counterparts while discards a few of the adverse effects. Thus, eluxadoline appears to be one of the most suitable opioids for alleviating abdominal pain and improving GI transit state in IBS-D patients without inducing severe constipation (62). However, common side effects of eluxadoline include constipation (69) especially in elderly patients with a higher rate of comorbid hepatic/biliary tract disease (62).

\section{Chloride Channel Activator}

Lubiprostone is a chloride channel activator approved by the FDA for treating female IBS-C patients $(70,71)$, which acts locally on the apical membrane of epithelial cells in the gastrointestinal lumen $(72,73)$. As a derivative of prostaglandin E1, lubiprostone selectively combines with 
prostaglandin receptor to activate chloride channel 2 leading to chloride-rich fluid secretion $(1,74)$. Increasing fluid secretion softens stools and improves intestinal motility, which finally contributes to alleviate constipation symptoms of IBS-C. The effect of lubiprostone is restricted to the GI tract as evidenced by its rapid metabolism within the lumen and low concentration of its metabolite $\mathrm{M} 3$ in the blood stream (75). Outcomes from two 12-week phase III clinical trials supported the efficacy of lubiprostone in mitigating global symptoms of IBS-C. An additional extension trial for 9-13 months confirmed the long-term safety and tolerability of lubiprostone in IBS-C patients. Adverse effects include nausea, diarrhea, flatulence, abdominal pain and vomiting (76). Lupiprostone cannot be used on pregnant women due to evidence of increased risk of fetal loss (70). However, no reported evidence has indicated that lubiprostone can significantly alleviate IBS pain. Thus, lubiprostone appears suitable for IBS patients with overt constipation while suffering from minor or moderate visceral pain.

\section{Guanylate Clyclase-C (GC-C) Agonist}

Linaclotide, a pH-independent 14-amino acid guanylate cyclase-C (GC-C) agonist, is an oral-intake drug for treating IBS-C approved by U.S. FDA and European medicines agency (1). It selectively binds to GC-C receptors in the GI tract to release intracellular cyclic guanosine-3, 5- monophosphate (cGMP), which activates the cystic fibrosis transmembrane conductance regulator $(70,75)$. Consequently, chloride and bicarbonate ions are secreted and sodium absorption is inhibited, leading to improved GI transit $(2,72)$. In addition, linaclotide was proven to act as an analgesic to alleviate visceral pain perception by inhibiting mechano-sensitivity of colorectal afferent neurons via synthesis of $\operatorname{cGMP}(72,77,78)$. Action of linaclotide is restricted to the GI tract due to its low bioavailability, rapid metabolism, and more importantly the restricted expression of its target, GC-C receptors within the intestinal mucosal layer (77). Hence, systemic exposure is minimal at normal doses $(71,74)$. The efficacy of linaclotide is supported by the outcomes of two phase III clinical trials on IBS-C patients from which alleviated abdominal pain and increased complete spontaneous bowel movement were reported $(79,80)$. The most common adverse effect is diarrhea which is well-tolerated. Linaclotide should not be used for human under age 18, and is in pregnancy category $C(71,72)$. Overall, linaclotide appears to be an ideal drug for IBS-C patients in the absence of any apparent side effects.

\section{Promising Novel Targets and Drugs For Ibs Pain}

Since IBS-related visceral pain is a severe healthcare burden and unmet clinical need, persistent efforts have been devoted to the quest for better medications for IBS with an emphasis on drugs targeting the periphery. Candidate molecules in the GI tract and visceral afferent neurons were thoroughly reviewed by Holzer (53). Additional molecular targets have been suggested by recent neuroscience and gastrointestinal research for next-generation drugs to treat IBS. We recently showed that voltage-gated sodium channel NaV1.6 plays necessary roles in repetitive spiking of mechanosensitive visceral afferents to colon stretch (81), the activation of which reliably evokes painful sensation in the viscera (82). Osteen et al. reported the presence of NaV1.1 in high-threshold mechanoreceptors innervating the colon and rectum and NaV1.1 was shown to regulate the excitability of sensory nerve fibers that medicate mechanical pain (83). Most recently, Castro et al. reported that activation of GABAB channels in colorectal afferent neurons reduced their excitability to mechanical colon stimuli via downstream effectors of two voltage gated calcium channels CaV2.2 and CaV2.3 (84).

In addition, a number of drugs for treating IBS have completed small scaled clinical trials with positive outcomes documented in the literature and will be reviewed below, including asimadoline, rifaximin, mesalamine, ketotifen and cromoglycate.

Asimadoline is a selective peripheral $\kappa$-opioid receptor agonist with significantly higher selectivity of $\kappa$ - over either $\delta$-or $\mu$-opioid receptors. Unlike a previous $\kappa$-opioid agonist fedotozine which failed to show significant efficacy in clinical trials (85), asimadoline has shown promising effects in treating IBS-D patients in a phase II clinical trial (86). Asimadoline have restricted effects within the GI tract due to its poor permeability through the blood brain barrier. The analgesic effect is presumably mediated by opioid receptors which reduces the excitability of nociceptors on peripheral nerve endings (87). Currently, phase III clinical trial of asimadoline in treating IBS-D patients has just been completed and the outcomes are yet to be released.

Rifaximin is a nonabsorbable antibiotic with restricted effect in the GI tract due to poor oral bioavailability. Rifaximin has been approved by the FDA for travelers' diarrhea and hepatic encephalopathy. Efficacy of rifaximin in treating IBS patients without constipation has been supported by five well-designed clinical trials (88). All five studies showed global improvement of IBS symptom by rifaximin and two studies reported alleviation of abdominal pain. After only a short treatment period (10 - 14 days), the efficacy of rifaximin was observed to persist up to 12 weeks (88). Adverse effects with rifaximin were minimum in clin- 
ical trials, including extremely low incidence of peripheral edema, dizziness, fatigue, and nausea (88). Current limitations of rifaximin includes its high cost and lack of clinical data from long-term studies on IBS patients.

Mesalamine, a 5-aminosalicylic acid is an antiinflammatory drug and extensively used for treating inflammatory bowel disease. The presence of low-grade inflammation and mucosal immune activation in IBS provides the rationale for using mesalamine in IBS patients. Mesalamine reportedly improved the global symptoms in a small trial of 20 patients with IBS (89) and reduced fecal bacterial counts in a separate trial on 12 IBS-D patients (90). Conflicting outcomes were received regarding the pain relieving effect of mesalamine from two other independent clinical trials $(91,92)$. Large scaled clinical studies are required to further determine the therapeutic efficacy of mesalamine in treating IBS pain.

Ketotifen as a mast cell stabilizer features a new type of treatment scheme for IBS aiming at the immune system in the GI tract. Ketotifen has been shown to prevent the activation of mucosal mast cells by cholecystokinin (CCK) (93). The efficacy of ketotifen for treating IBS is supported by a clinical trial on 60 IBS patients (94). Ketotifen significantly decreased abdominal pain in IBS patients as indicated by increased discomfort threshold to rectal balloon distension. In addition, the number of mast cells in rectal biopsies and spontaneous release of tryptase were lower in IBS patients receiving Ketotifen. Adverse effects including sedation and drowsiness were mild and well tolerated. However, the exact mechanism of the above clinical benefits is unclear as ketotifen did not alter histamine and tryptase release. Further studies are needed to define the role of ketotifen for the treatment of IBS.

Cromoglycate is another investigational drug that target intestinal mast cells, inhibiting their release of mediators including histamine, leukotrienes and a slow reacting substance of anaphylaxis. Effect of cromoglycate in treating IBS-D patients with food intolerance was supported by a clinical study on 66 IBS-D patients selected from 120 IBSD population showing concomitant symptoms of food intolerance (95). The cohort that received both cromoglycate and strict exclusion diet treatment showed significant improvement of global IBS symptoms whereas the other cohort receiving diet treatment alone only had moderate improvement. However, no specific assay to assess the painrelieving effect was designed in that study. A recent clinical study on 18 general IBS patients reported beneficial effects of cromoglycate, which include reduced release of tryptase from intestinal biopsies, attenuated expression of TLR2 and TLR4, and clinical improvement of bowel function in the IBS-D subgroup $(96,97)$. Effect of cromoglycate in treating abdominal pain and other symptoms in differ- ent subgroups of IBS needs to be studied in a larger number of patients.

\section{Conclusions}

Visceral pain associated with IBS differs greatly from other types of pain and requires special pharmacological managements. Certain conventional drugs for relieving pain do not significantly improve IBS symptoms based upon negative or lack of clinical and research data, including NSAIDs, acetaminophen, aspirin, and various narcotics. IBS patients with comorbidities of anxiety and/or depression may benefit from anxiolytic (benzodiazepine) and antidepressant drugs (TCAs, SSRI and SNRI). Drugs that effectively manage neuropathic pain disorders (gabapentin and pregabalin) reportedly improved global IBS symptoms and alleviated visceral pain, which requires further confirmation. Clonidine appears to be the only conventional pain-managing drug that benefits the general IBS population.

Medications that target the GI tract and peripheral nerves have better therapeutic profiles by limiting adverse CNS effects. The optimal drugs for managing pain in IBS$\mathrm{D}$ and IBS-C patients appear to be eluxadoline and linaclotide, respectively. Lubiprostone effectively relieves constipation symptoms in IBS-C but has no apparent painrelieving effect. Loperamide is efficacious in managing diarrhea symptoms but tends to tip the balance towards constipation, which limits its usage at a higher dose to relieve pain. The 5HT3 antagonists alosetron, granisetron and ondansetron can benefit IBS-D patients, among which alosetron needs to be used with caution due to potential cardiovascular toxicity. Promising investigational drugs for treating IBS pain include asimadoline, rifaximin, mesalamine, ketotifen and cromoglycate.

\section{Acknowledgments}

This study is supported by the United States national institute of health (NIH) research grant DK100460 to Dr. Bin Feng.

\section{Footnote}

Financial Disclosure: Dr. Bin Feng has a study contract with Allergan Inc. to investigate the effect of eluxadoline on visceral afferents. 


\section{References}

1. Nusrat S, Miner PJ. New pharmacological treatment options for irritable bowel syndrome with constipation. Expert Opin Emerg Drugs. 2015;20(4):625-36. doi: 10.1517/14728214.2015.1105215. [PubMed: 26548544].

2. Furnari M, de Bortoli N, Martinucci I, Bodini G, Revelli M, Marabotto E, et al. Optimal management of constipation associated with irritable bowel syndrome. Ther Clin Risk Manag. 2015;11:691-703. doi: 10.2147/TCRM.S54298. [PubMed: 26028974].

3. Longstreth GF, Thompson WG, Chey WD, Houghton LA, Mearin F, Spiller RC. Functional bowel disorders. Gastroenterology. 2006;130(5):1480-91. doi: 10.1053/j.gastro.2005.11.061. [PubMed: 16678561].

4. Feng B, La JH, Schwartz ES, Gebhart GF. Irritable bowel syndrome: methods, mechanisms, and pathophysiology. Neural and neuroimmune mechanisms of visceral hypersensitivity in irritable bowel syndrome. Am J Physiol Gastrointest Liver Physiol. 2012;302(10):G108598. doi: 10.1152/ajpgi.00542.2011. [PubMed: 22403791].

5. Engsbro AL, Simren M, Bytzer P. The Rome II and Rome III criteria identify the same subtype-populations in irritable bowel syndrome: agreement depends on the method used for symptom report. Neurogastroenterol Motil. 2012;24(7):604-11. doi: 10.1111/j.13652982.2012.01908.x. [PubMed: 22420629] e266.

6. Palsson OS, Whitehead WE, van Tilburg MA, Chang L, Chey W, Crowell MD, et al. Rome IV Diagnostic Questionnaires and Tables for Investigators and Clinicians. Gastroenterology. 2016 doi: 10.1053/j.gastro.2016.02.014. [PubMed: 27144634].

7. Videlock EJ, Adeyemo M, Licudine A, Hirano M, Ohning G, Mayer M, et al. Childhood trauma is associated with hypothalamic-pituitaryadrenal axis responsiveness in irritable bowel syndrome. Gastroenterology. 2009;137(6):1954-62. doi: 10.1053/j.gastro.2009.08.058. [PubMed: 19737564].

8. Chitkara DK, van Tilburg MA, Blois-Martin N, Whitehead WE. Early life risk factors that contribute to irritable bowel syndrome in adults: a systematic review. Am J Gastroenterol. 2008;103(3):765-74. doi: 10.1111/j.1572-0241.2007.01722.x. [PubMed: 18177446] quiz 775.

9. North CS, Hong BA, Alpers DH. Relationship of functional gastrointestinal disorders and psychiatric disorders: implications for treatment. World J Gastroenterol. 2007;13(14):2020-7. [PubMed: 17465442].

10. Saito YA, Talley NJ. Genetics of irritable bowel syndrome. Am J Gastroenterol. 2008;103(8):2100-4. doi: 10.1111/j.1572-0241.2008.02048.x. [PubMed: 18684190] quiz 2105.

11. Fukudo S, Kanazawa M. Gene, environment, and brain-gut interactions in irritable bowel syndrome. J Gastroenterol Hepatol. 2011;26 Suppl 3:110-5. doi: 10.1111/j.1440-1746.2011.06631.x. [PubMed: 21443722].

12. Marynowski M, Likonska A, Zatorski H, Fichna J. Role of environmental pollution in irritable bowel syndrome. World J Gastroenterol. 2015;21(40):11371-8. doi: 10.3748/wjg.v21.i40.11371. [PubMed: 26523104].

13. Schwille-Kiuntke J, Mazurak N, Enck P. Systematic review with meta-analysis: post-infectious irritable bowel syndrome after travellers' diarrhoea. Aliment Pharmacol Ther. 2015;41(11):1029-37. doi: 10.1111/apt.13199. [PubMed: 25871571].

14. Piche T. Tight junctions and IBS-the link between epithelial permeability, low-grade inflammation, and symptom generation? Neurogastroenterol Motil. 2014;26(3):296-302. doi: 10.1111/nmo.12315. [PubMed: 24548256].

15. Collins SM. A role for the gut microbiota in IBS. Nat Rev Gastroenterol Hepatol. 2014;11(8):497-505. doi: 10.1038/nrgastro.2014.40. [PubMed: 24751910].

16. Mayer EA, Tillisch K. The brain-gut axis in abdominal pain syndromes. Annu Rev Med. 2011;62:381-96. doi: 10.1146/annurev-med012309-103958. [PubMed: 21090962].

17. Price DD, Zhou Q, Moshiree B, Robinson ME, Verne GN. Peripheral and central contributions to hyperalgesia in irritable bowel syndrome.
J Pain. 2006;7(8):529-35. doi: 10.1016/j.jpain.2005.12.011. [PubMed: 16885007].

18. Feng B, La JH, Schwartz ES, Tanaka T, McMurray TP, Gebhart GF. Longterm sensitization of mechanosensitive and -insensitive afferents in mice with persistent colorectal hypersensitivity. Am J Physiol Gastrointest Liver Physiol. 2012;302(7):G676-83. doi: 10.1152/ajpgi.00490.2011. [PubMed: 22268098].

19. Feng B, La JH, Tanaka T, Schwartz ES, McMurray TP, Gebhart GF. Altered colorectal afferent function associated with TNBS-induced visceral hypersensitivity in mice. Am J Physiol Gastrointest Liver Physiol. 2012;303(7):G817-24. doi: 10.1152/ajpgi.00257.2012. [PubMed: 22859364].

20. Zhou Q, Price DD, Verne GN. Reversal of visceral and somatic hypersensitivity in a subset of hypersensitive rats by intracolonic lidocaine. Pain. 2008;139(1):218-24. doi: 10.1016/j.pain.2008.04.002. [PubMed: 18486344].

21. Verne GN, Robinson ME, Vase L, Price DD. Reversal of visceral and cutaneous hyperalgesia by local rectal anesthesia in irritable bowel syndrome(IBS) patients. Pain. 2003;105(1-2):223-30. [PubMed:14499439].

22. Verne GN, Sen A, Price DD. Intrarectal lidocaine is an effective treatment for abdominal pain associated with diarrheapredominant irritable bowel syndrome. J Pain. 2005;6(8):493-6. doi: 10.1016/j.jpain.2005.02.009. [PubMed: 16084463].

23. Louvel D, Delvaux M, Staumont G, Camman F, Fioramonti J, Bueno $\mathrm{L}$, et al. Intracolonic injection of glycerol: a model for abdominal pain in irritable bowel syndrome? Gastroenterology. 1996;110(2):35161. [PubMed: 8566580].

24. Al-Chaer ED. Neuroanatomy of Visceral Pain. Chronic abdominal and visceral pain: Theory and practice. CRC Press; 2007.

25. Locke G3, Zinsmeister AR, Talley NJ, Fett SL, Melton LJ. Risk factors for irritable bowel syndrome: role of analgesics and food sensitivities. Am J Gastroenterol. 2000;95(1):157-65. doi: 10.1111/j.15720241.2000.01678.x. [PubMed: 10638576].

26. Keszthelyi D, Dackus GH, Masclee GM, Kruimel JW, Masclee AA. Increased proton pump inhibitor and NSAID exposure in irritable bowel syndrome: results from a case-control study. BMC Gastroenterol. 2012;12:121. doi: 10.1186/1471-230X-12-121. [PubMed: 22950677].

27. Kerckhoffs AP, Akkermans LM, de Smet MB, Besselink MG, Hietbrink F, Bartelink IH, et al. Intestinal permeability in irritable bowel syndrome patients: effects of NSAIDs. Dig Dis Sci. 2010;55(3):716-23. doi: 10.1007/s10620-009-0765-9. [PubMed: 19255843].

28. Thiefin G, Beaugerie L. Toxic effects of nonsteroidal antiinflammatory drugs on the small bowel, colon, and rectum. Joint Bone Spine. 2005;72(4):286-94. doi:10.1016/j.jbspin.2004.10.004. [PubMed: 16038840].

29. Higuchi K, Umegaki E, Watanabe T, Yoda Y, Morita E, Murano M, et al. Present status and strategy of NSAIDs-induced small bowel injury. J Gastroenterol. 2009;44(9):879-88. doi: 10.1007/s00535-009-0102-2. [PubMed: 19568687].

30. Hinson JA, Roberts DW, James LP. Mechanisms of acetaminopheninduced liver necrosis. Handb Exp Pharmacol. 2010(196):369-405. doi: 10.1007/978-3-642-00663-0_12. [PubMed: 20020268].

31. Soleimanpour M, Imani F, Safari S, Sanaie S, Soleimanpour H, Ameli $\mathrm{H}$, et al. The Role of Non-Steroidal Anti-Inflammatory Drugs (NSAIDs) in the Treatment of Patients With Hepatic Disease: A Review Article. Anesth Pain Med. 2016;6(4):ee37822. doi: 10.5812/aapm.37822. [PubMed: 27843779].

32. Szigethy E, Schwartz M, Drossman D. Narcotic bowel syndrome and opioid-induced constipation. Curr Gastroenterol Rep. 2014;16(10):410. doi: 10.1007/s11894-014-0410-4. [PubMed: 25183577].

33. Drossman D, Szigethy E. The narcotic bowel syndrome: a recent update. Am J Gastroenterol Suppl. 2014;2(1):22-30. doi: 10.1038/ajgsup.2014.6. [PubMed: 25207609].

34. Munro G, Hansen RR, Mirza NR. GABA(A) receptor modulation: potential to deliver novel pain medicines? Eur J Pharmacol. 2013;716(1-3):1723. doi: 10.1016/j.ejphar.2013.01.070. [PubMed: 23500203]. 
35. Lader M. Effectiveness of benzodiazepines: do they work or not? Expert Rev Neurother. 2008;8(8):1189-91. doi: 10.1586/14737175.8.8.1189. [PubMed: 18671662].

36. Salari P, Abdollahi M. Systematic review of modulators of benzodiazepine receptors in irritable bowel syndrome: is there hope? World J Gastroenterol. 2011;17(38):4251-7. doi: 10.3748/wjg.v17.i38.4251. [PubMed: 22090780].

37. Leventer SM, Raudibaugh K, Frissora CL, Kassem N, Keogh JC, Phillips J, et al. Clinical trial: dextofisopam in the treatment of patients with diarrhoea-predominant or alternating irritable bowel syndrome. Aliment Pharmacol Ther. 2008;27(2):197-206. doi: 10.1111/j.13652036.2007.03566.x. [PubMed: 17973974].

38. Rahimi R, Nikfar S, Rezaie A, Abdollahi M. Efficacy of tricyclic antidepressants in irritable bowel syndrome: a meta-analysis. World J Gastroenterol. 2009;15(13):1548-53. [PubMed:19340896].

39. Xie C, Tang Y, Wang Y, Yu T, Wang Y, Jiang L, et al. Efficacy and Safety of Antidepressants for the Treatment of Irritable Bowel Syndrome: A Meta-Analysis. PLoS One. 2015;10(8):e0127815. doi: 10.1371/journal.pone.0127815. [PubMed: 26252008].

40. Vahedi H, Merat S, Rashidioon A, Ghoddoosi A, Malekzadeh R. The effect of fluoxetine in patients with pain and constipationpredominant irritable bowel syndrome: a double-blind randomizedcontrolled study. Aliment Pharmacol Ther. 2005;22(5):381-5. doi: 10.1111/j.1365-2036.2005.02566.x. [PubMed:16128675].

41. Kuiken SD, Tytgat GN, Boeckxstaens GE. The selective serotonin reuptake inhibitor fluoxetine does not change rectal sensitivity and symptoms in patients with irritable bowel syndrome: a double blind, randomized, placebo-controlled study. Clin Gastroenterol Hepatol. 2003;1(3):219-28. doi: 10.1053/cgh.2003.50032. [PubMed: 15017494].

42. Tack I, Broekaert D, Fischler B, Van Oudenhove L, Gevers AM, Janssens J. A controlled crossover study of the selective serotonin reuptake inhibitor citalopram in irritable bowel syndrome. Gut. 2006;55(8):1095-103. doi: 10.1136/gut.2005.077503. [PubMed: 16401691].

43. Talley NJ, Kellow JE, Boyce P, Tennant C, Huskic S, Jones M. Antidepressant therapy (imipramine and citalopram) for irritable bowel syndrome: a double-blind, randomized, placebo-controlled trial. Dig Dis Sci. 2008;53(1):108-15. doi: 10.1007/s10620-007-9830-4. [PubMed: 17503182].

44. Ladabaum U, Sharabidze A, Levin TR, Zhao WK, Chung E, Bacchetti $\mathrm{P}$, et al. Citalopram provides little or no benefit in nondepressed patients with irritable bowel syndrome. Clin Gastroenterol Hepatol. 2010;8(1):42-48 e1. doi: 10.1016/j.cgh.2009.09.008. [PubMed: 19765674].

45. Tabas G, Beaves M, Wang J, Friday P, Mardini H, Arnold G. Paroxetine to treat irritable bowel syndrome not responding to highfiber diet: a double-blind, placebo-controlled trial. Am J Gastroenterol. 2004;99(5):914-20. doi: 10.1111/j.1572-0241.2004.04127.x. [PubMed: 15128360]

46. Camilleri M, Busciglio I, Carlson P, McKinzie S, Burton D, Baxter $\mathrm{K}$, et al. Pharmacogenetics of low dose clonidine in irritable bowel syndrome. Neurogastroenterol Motil. 2009;21(4):399-410. doi: 10.1111/j.1365-2982.2009.01263.x. [PubMed: 19309415].

47. Viramontes BE, Malcolm A, Camilleri M, Szarka LA, McKinzie S, Burton DD, et al. Effects of an alpha(2)-adrenergic agonist on gastrointestinal transit, colonic motility, and sensation in humans. Am J Physiol Gastrointest Liver Physiol. 2001;281(6):G1468-76. [PubMed: 11705752].

48. Gilron I, Baron R, Jensen T. Neuropathic pain: principles of diagnosis and treatment. Mayo Clin Proc. 2015;90(4):532-45. doi: 10.1016/j.mayocp.2015.01.018. [PubMed: 25841257].

49. Imani F, Rahimzadeh P. Gabapentinoids: gabapentin and pregabalin for postoperative pain management. Anesth Pain Med. 2012;2(2):52-3. doi: 10.5812/aapm.7743. [PubMed: 24223337].

50. Lee KJ, Kim JH, Cho SW. Gabapentin reduces rectal mechanosensitivity and increases rectal compliance in patients with diarrhoeapredominant irritable bowel syndrome. Aliment Pharmacol Ther.
2005;22(10):981-8. doi: 10.1111/j.1365-2036.2005.02685.x. [PubMed: 16268973].

51. Houghton LA, Fell C, Whorwell PJ, Jones I, Sudworth DP, Gale JD. Effect of a second-generation alpha2delta ligand (pregabalin) on visceral sensation in hypersensitive patients with irritable bowel syndrome. Gut. 2007;56(9):1218-25. doi: 10.1136/gut.2006.110858. [PubMed: 17446306].

52. Gold MS, Gebhart GF. Nociceptor sensitization in pain pathogen esis. Nat Med. 2010;16(11):1248-57. doi: 10.1038/nm.2235. [PubMed 20948530].

53. Wultsch T, Painsipp E, Shahbazian A, Mitrovic M, Edelsbrunner $M$, Lazdunski $M$, et al. Deletion of the acid-sensing ion channel ASIC3 prevents gastritis-induced acid hyperresponsiveness of the stomach-brainstem axis. Pain. 2008;134(3):245-53. doi 10.1016/j.pain.2007.04.025. [PubMed: 17531389].

54. Manning DD, Guo C, Zhang Z, Ryan KN, Naginskaya J, Choo $\mathrm{SH}$, et al. The discovery of diazepinone-based 5-HT3 receptor partial agonists. Bioorg Med Chem Lett. 2014;24(11):2578-81. doi 10.1016/j.bmcl.2014.03.074. [PubMed: 24755431].

55. Gilet M, Eutamene H, Han H, Kim HW, Bueno L. Influence of a new 5HT4 receptor partial agonist, YKP10811, on visceral hypersensitivity in rats triggered by stress and inflammation. Neurogastroenterol Motil. 2014;26(12):1761-70. doi:10.1111/nmo.12458. [PubMed: 25316608].

56. Cremon C, Carini G, Wang B, Vasina V, Cogliandro RF, De Giorgio $\mathrm{R}$, et al. Intestinal serotonin release, sensory neuron activation, and abdominal pain in irritable bowel syndrome. Am J Gastroenterol. 2011;106(7):1290-8. doi: 10.1038/ajg.2011.86. [PubMed: 21427712].

57. Moore NA, Sargent BJ, Manning DD, Guzzo PR. Partial agonism of 5 HT3 receptors: a novel approach to the symptomatic treatment of IBS D. ACS Chem Neurosci. 2013;4(1):43-7. doi:10.1021/cn300166c. [PubMed: 23342199].

58. Cash BD, Lacy BE, Rao T, Earnest DL. Rifaximin and eluxadoline - newly approved treatments for diarrhea-predominant irritable bowel syndrome: what is their role in clinical practice alongside alosetron? Expert Opin Pharmacother. 2016;17(3):311-22. doi 10.1517/14656566.2016.1118052. [PubMed: 26559529].

59. Gershon MD, Tack J. The serotonin signaling system: from basic understanding to drug development for functional GI disorders. Gastroenterology. 2007;132(1):397-414. doi: 10.1053/j.gastro.2006.11.002. [PubMed: 17241888].

60. Goldberg PA, Kamm MA, Setti-Carraro P, van der Sijp JR, Roth C. Modification of visceral sensitivity and pain in irritable bowel syndrome by 5-HT3 antagonism (ondansetron). Digestion. 1996;57(6):478-83. [PubMed: 8913711].

61. Garsed K, Chernova J, Hastings M, Lam C, Marciani L, Singh G, et al. A randomised trial of ondansetron for the treatment of irritable bowel syndrome with diarrhoea. Gut. 2014;63(10):1617-25. doi:10.1136/gutjnl2013-305989. [PubMed: 24334242].

62. Scarpellini E, Laterza L, Ianiro G, Tack J, Abenavoli L, Gasbarrini A Eluxadoline for the treatment of diarrhoea-predominant irritable bowel syndrome. Expert Opin Pharmacother. 2016;17(10):1395-402. doi: 10.1080/14656566.2016.1182982. [PubMed: 27267380].

63. Lacy BE. Emerging treatments in neurogastroenterology: eluxadoline - a new therapeutic option for diarrhea-predominant IBS. Neurogastroenterol Motil. 2016;28(1):26-35. doi: 10.1111/nmo.12716. [PubMed: 26690872].

64. Lavo B, Stenstam M, Nielsen AL. Loperamide in treatment of irritable bowel syndrome-a double-blind placebo controlled study. Scand J Gastroenterol Suppl. 1987;130:77-80. [PubMed: 3306903].

65. Efskind PS, Bernklev T, Vatn MH. A double-blind placebo-controlled trial with loperamide in irritable bowel syndrome. Scand J Gastroenterol. 1996;31(5):463-8. doi: 10.3109/00365529609006766. [PubMed: 8734343]

66. Cann PA, Read NW, Holdsworth CD, Barends D. Role of loperamide and placebo in management of irritable bowel syndrome (IBS). Dig 
Dis Sci. 1984;29(3):239-47. [PubMed: 6365490].

67. Wade PR, Palmer JM, McKenney S, Kenigs V, Chevalier K, Moore BA, et al. Modulation of gastrointestinal function by MuDelta, a mixed micro opioid receptor agonist/ micro opioid receptor antagonist. $\mathrm{Br}$ J Pharmacol. 2012;167(5):1111-25. doi: 10.1111/j.1476-5381.2012.02068.x. [PubMed: 22671931].

68. Sobolewska-Wlodarczyk A, Wlodarczyk M, Storr M, Fichna J. Clinical potential of eluxadoline in the treatment of diarrhea-predominant irritable bowel syndrome. Ther Clin Risk Manag. 2016;12:771-5. doi: 10.2147/TCRM.S83722. [PubMed: 27257381].

69. Lembo AJ, Lacy BE, Zuckerman MJ, Schey R, Dove LS, Andrae DA, et al. Eluxadoline for Irritable Bowel Syndrome with Diarrhea. NEngl J Med. 2016;374(3):242-53. doi: 10.1056/NEJMoa1505180. [PubMed: 26789872].

70. Wall GC, Bryant GA, Bottenberg MM, Maki ED, Miesner AR. Irritable bowel syndrome: a concise review of current treatment concepts. World J Gastroenterol. 2014;20(27):8796-806. doi: 10.3748/wjg.v20.i27.8796. [PubMed: 25083054].

71. Thomas RH, Luthin DR. Current and emerging treatments for irritable bowel syndrome with constipation and chronic idiopathic constipation: focus on prosecretory agents. Pharmacotherapy. 2015;35(6):613-30. doi: 10.1002/phar.1594. [PubMed: 26016701].

72. RaoS, Weber HC. New treatment targets for the management of irritable bowel syndrome. Curr Opin Endocrinol Diabetes Obes. 2014;21(1):914. doi: 10.1097/MED.0000000000000034. [PubMed: 24300740].

73. Corsetti M, Whorwell P. Novel pharmacological therapies for irritable bowel syndrome. Expert Rev Gastroenterol Hepatol. 2016;10(7):807-15. doi: 10.1586/17474124.2016.1158099. [PubMed: 26907518].

74. Mozaffari S, Nikfar S, Abdollahi M. The safety of novel drugs used to treat irritable bowel syndrome. Expert Opin Drug Saf. 2014;13(5):62538. doi: 10.1517/14740338.2014.902932. [PubMed: 24669839].

75. Jiang C, Xu Q, Wen X, Sun H. Current developments in pharmacological therapeutics for chronic constipation. Acta Pharm Sin B. 2015;5(4):300-9. doi: 10.1016/j.apsb.2015.05.006. [PubMed: 26579459].

76. Drossman DA, Chey WD, Johanson JF, Fass R, Scott C, Panas R, et al. Clinical trial: lubiprostone in patients with constipationassociated irritable bowel syndrome-results of two randomized, placebo-controlled studies. Aliment Pharmacol Ther. 2009;29(3):32941. doi: 10.1111/j.1365-2036.2008.03881.x. [PubMed: 19006537].

77. Feng B, Kiyatkin ME, La JH, Ge P, Solinga R, Silos-Santiago I, et al. Activation of guanylate cyclase- $C$ attenuates stretch responses and sensitization of mouse colorectal afferents. J Neurosci. 2013;33(23):9831-9. doi: 10.1523/JNEUROSCI.5114-12.2013. [PubMed: 23739979].

78. Tack J, Vanuytsel T, Corsetti M. Modern Management of Irritable Bowel Syndrome: More Than Motility. Dig Dis. 2016;34(5):566-73. doi: 10.1159/000445265. [PubMed: 27331917].

79. Rao S, Lembo AJ, Shiff SJ, Lavins BJ, Currie MG, Jia XD, et al. A 12-week, randomized, controlled trial with a 4-week randomized withdrawal period to evaluate the efficacy and safety of linaclotide in irritable bowel syndrome with constipation. Am J Gastroenterol. 2012;107(11):1714-24. doi: 10.1038/ajg.2012.255. [PubMed: 22986440] quiz p 1725.

80. Chey WD, Lembo AJ, Lavins BJ, Shiff SJ, Kurtz CB, Currie MG, et al. Linaclotide for irritable bowel syndrome with constipation: a 26week, randomized, double-blind, placebo-controlled trial to evaluate efficacy and safety. Am J Gastroenterol. 2012;107(11):1702-12. doi: 10.1038/ajg.2012.254. [PubMed: 22986437].

81. Feng B, Zhu Y, La JH, Wills ZP, Gebhart GF. Experimental and computational evidence for an essential role of NaV1.6 in spike initiation at stretch-sensitive colorectal afferent endings. J Neurophysiol. 2015;113(7):2618-34. doi: 10.1152/jn.00717.2014. [PubMed: 25652923].

82. Ness TJ, Metcalf AM, Gebhart GF. A psychophysiological study in humans using phasic colonic distension as a noxious visceral stimulus.
Pain. 1990;43(3):377-86. [PubMed: 2293146].

83. Osteen JD, Herzig V, Gilchrist J, Emrick JJ, Zhang C, Wang X, et al. Selective spider toxins reveal a role for the Nav1.1 channel in mechanical pain. Nature. 2016;534(7608):494-9. doi: 10.1038/nature17976. [PubMed: 27281198].

84. Castro J, Harrington AM, Garcia-Caraballo S, Maddern J, Grundy L, Zhang J, et al. alpha-Conotoxin Vc1.1 inhibits human dorsal root ganglion neuroexcitability and mouse colonic nociception via GABAB receptors. Gut. 2016 doi: 10.1136/gutjnl-2015-310971. [PubMed: 26887818].

85. Lembo A. Peripheral opioids for functional GI disease: a reappraisal. Dig Dis. 2006;24(1-2):91-8. doi: 10.1159/000090312. [PubMed: 16699267].

86. Mangel AW, Williams VS. Asimadoline in the treatment of irritable bowel syndrome. Expert Opin Investig Drugs. 2010;19(10):1257-64. doi: 10.1517/13543784.2010.515209. [PubMed: 20809870].

87. Camilleri M. Novel pharmacology: asimadoline, a kappa-opioid agonist, and visceral sensation. Neurogastroenterol Motil. 2008;20(9):9719. doi: 10.1111/j.1365-2982.2008.01183.x. [PubMed: 18715494].

88. Menees SB, Maneerattannaporn M, Kim HM, Chey WD. The efficacy and safety of rifaximin for the irritable bowel syndrome: a systematic review and meta-analysis. Am J Gastroenterol. 2012;107(1):28-35. doi: 10.1038/ajg.2011.355. [PubMed: 22045120] quiz 36.

89. Corinaldesi R, Stanghellini V, Cremon C, Gargano L, Cogliandro RF, De Giorgio R, et al. Effect of mesalazine on mucosal immune biomarkers in irritable bowel syndrome: a randomized controlled proofof-concept study. Aliment Pharmacol Ther. 2009;30(3):245-52. doi: 10.1111/j.1365-2036.2009.04041.x. [PubMed: 19438846].

90. Andrews CN, Griffiths TA, Kaufman J, Vergnolle N, Surette MG, Rioux KP. Mesalazine (5-aminosalicylic acid) alters faecal bacterial profiles, but not mucosal proteolytic activity in diarrhoea-predominant irritable bowel syndrome. Aliment Pharmacol Ther. 2011;34(3):374-83. doi: 10.1111/j.1365-2036.2011.04732.x. [PubMed: 21671966].

91. Dorofeyev AE, Kiriyan EA, Vasilenko IV, Rassokhina OA, Elin AF. Clinical, endoscopical and morphological efficacy of mesalazine in patients with irritable bowel syndrome. Clin Exp Gastroenterol. 2011;4:141-53. doi: 10.2147/CEG.S18381. [PubMed: 21753896].

92. Tuteja AK, Fang JC, Al-Suqi M, Stoddard GJ, Hale DC. Double-blind placebo-controlled study of mesalamine in post-infective irritable bowel syndrome-a pilot study. Scand J Gastroenterol. 2012;47(10):115964. doi: 10.3109/00365521.2012.694903. [PubMed: 22783919].

93. Gay J, Ressayre L, Garcia-Villar R, Bueno L, Fioramonti J. Alteration of CCK-induced satiety in post-Nippostrongylus brasiliensis-infected rats. Brain Behav Immun. 2003;17(1):35-42. [PubMed: 12615048].

94. Klooker TK, Braak B, Koopman KE, Welting O, Wouters MM, van der Heide $S$, et al. The mast cell stabiliser ketotifen decreases visceral hypersensitivity and improves intestinal symptoms in patients with irritable bowel syndrome. Gut. 2010;59(9):1213-21. doi: 10.1136/gut.2010.213108. [PubMed: 20650926].

95. Leri O, Tubili S, De Rosa FG, Addessi MA, Scopelliti G, Lucenti W, et al. Management of diarrhoeic type of irritable bowel syndrome with exclusion diet and disodium cromoglycate. Inflammopharmacology. 1997;5(2):153-8. doi: 10.1007/s10787-997-0024-7. [PubMed: 17694364].

96. Lobo B, Vicario M, Martinez C, Ramos L, Alonso C, Guilarte M, et al. 156 Clinical Benefit in IBS After Disodium Cromoglycate Involves Mast Cell-Mediated Recovery of Healthy-Like Innate Immunity Genes Expression Profile in the Jejunal Mucosa. Gastroenterology. 2009;136(5):A-30. doi: 10.1016/s0016-5085(09)60139-6.

97. Lobo B, Vicario M, Martinez C, Gonzalez-Castro AM, Ramos L, Alonso $\mathrm{C}$, et al. Clinical improvement in IBS after disodium cromoglycate involves mast cell-mediated toll-like receptor signaling downregulation. Gastroenterology. 2011;140(5):S-499-S-500. 